\title{
A AGENDA 2030 DAS NAÇÕES UNIDAS E AS ENERGIAS RENOVÁVEIS NO BRASIL
}

Rafael Leão'

Este texto é uma resenha de Morais, José Mauro de. ${ }^{2}$ Caderno ODS 7: assegurar o acesso confiável, sustentável, moderno e a preço acessivel à energia para todos. Brasilia: Ipea, 2019. Disponivel em: <https://bit.ly/2PUeWPL>.

\section{SINOPSE}

Em A Agenda 2030 das Naçôes Unidas e as Energias Renováveis no Brasil, é apresentado o trabalho do pesquisador José Mauro de Morais, que elaborou o relatório de acompanhamento do ODS 7, com o objetivo de apresentar uma análise inicial sobre a utilização de energias limpas no Brasil, e verificar se o sistema de fornecimento de energia oferece serviços a preços acessíveis aos consumidores. $\mathrm{O}$ autor também avaliou se o país vem desenvolvendo políticas públicas que estimulem a utilização mais intensiva de energias renováveis, e se estas são coerentes com a implementação das metas acordadas no âmbito da Agenda 2030.

Palavras-chave: ODS; Agenda 2030; ONU; energia renovável.

\section{INTRODUÇÃO}

O uso intenso de fontes renováveis na geração de eletricidade e a produção crescente de biocombustíveis apontam o Brasil como referência mundial em energias limpas, com baixa emissão relativa de gases poluentes na atmosfera. A participação das fontes renováveis na capacidade instalada de geração do país é de $83,0 \%$, enquanto a média mundial alcança 33\% (REN21, 2019). Assim, 67\% da capacidade instalada de geraçáo elétrica mundial ainda dependem de fontes não renováveis, como o petróleo, o carvão e as usinas nucleares. No final de 2017 , segundo dados da Pesquisa Nacional por Amostra de Domicílios (PNAD), 99,8\% dos domicílios permanentes no Brasil tinham acesso à eletricidade, em um universo de 69,4 milhôes de unidades residenciais. Esses são alguns dos pontos centrais do diagnóstico sobre a situação do Brasil em relação ao Objetivo do Desenvolvimento Sustentável (ODS) 7: assegurar o acesso confiável, sustentável, moderno e a preço acessível à energia para todos.

Este artigo é uma síntese da publicação do Ipea Caderno ODS 7, um dos relatórios correspondentes aos dezessete ODS da Agenda 2030, da Organização das Naçôes Unidas (ONU). Os ODS visam contribuir para o aprimoramento das políticas públicas com vistas à erradicação da pobreza e à melhoria da qualidade de vida. Para a elaboração do relatório, foram consultadas bases de dados e informaçóes estatísticas sobre energia fornecidas pelo Ministério de Minas e Energia (MME), pela Agência Nacional de Energia Elétrica (Aneel), pela Empresa de Pesquisa Energética (EPE) e pelo Instituto Brasileiro de Geografia e Estatística (IBGE), além de referências acadêmicas e legislaçóes pertinentes ao assunto.

1. Especialista em políticas públicas e gestão governamental na Diretoria de Estudos e Políticas Setoriais de Inovação e Infraestrutura (Diset) do Ipea e editor deste Radar.

2. Técnico de planejamento e pesquisa na Diset/lpea. 


\section{AS CINCO METAS DO ODS 7}

A ONU estipulou cinco metas para o ODS 7: 7.1, 7.2, 7.3, 7.a e 7.b. No processo de internalização das metas, três delas foram ajustadas à realidade brasileira $(7.2,7.3$ e $7 . b)$.

Meta $7.1(O N U)$ - Até 2030, assegurar o acesso universal, confiável, moderno e a preços acessiveis a serviços de energia.

\section{Meta 7.1 (Brasil) - Meta mantida sem alteração.}

Segundo dados de 2017 da PNAD, 99,8\% dos domicílios brasileiros tinham acesso à eletricidade, sendo $99,2 \%$ com fornecimento integral, $0,3 \%$ com fornecimento parcial e $0,3 \%$ com energia de produção própria. Apenas 0,2\% das moradias brasileiras (cerca de 140 mil) ainda não possuem acesso algum à energia elétrica.

A qualidade do fornecimento da energia elétrica por unidade consumidora é monitorada permanentemente pela Aneel por meio de dois indicadores básicos:

- duração equivalente de interrupção (DEC) - quanto tempo, em média, o consumidor fica sem energia em um dado período; e

- frequência equivalente de interrupção (FEC) - quantas vezes faltou energia em um dado período.

Apesar das variaçóes regionais na qualidade do fornecimento de energia, pois algumas distribuidoras ainda ultrapassam os limites regulatórios, principalmente o limite de duraçáo das interrupçóes fixado pela Aneel, a energia está disponível aos consumidores, em média, em 99,85\% do tempo ao longo do ano. Em 2017, as compensaçóes financeiras aos consumidores em virtude de não cumprimento das metas por parte de algumas empresas fornecedoras de eletricidade foram da ordem de $\mathrm{R} \$ 490$ milhóes.

A matriz de energia elétrica brasileira é uma das mais limpas, mas também uma das mais caras do mundo. Alguns fatores operacionais e climáticos como a sazonalidade das chuvas e as baixas pluviométricas dos últimos anos são parte do problema, por terem demandado acionamentos frequentes das usinas termelétricas. Contudo, decisóes regulatórias e de políticas públicas parecem ter mais importância na explicação do encarecimento do fornecimento de eletricidade nos últimos anos. São exemplos de intervençóes no setor de energia: descontos tarifários para alguns setores/atividades (como empresas de serviços públicos de saneamento) e para alguns tipos de consumidores (classe rural e domicílios de baixa renda), subsídios para financiar fontes alternativas e aumentos tarifários corretivos, a partir de 2015, para compensar as reduçóes decididas pelo governo federal às concessionárias, em 2012.

TABELA 1

Tarifas de energia elétrica por setor, com tributos (2012-2018)

\begin{tabular}{|c|c|c|c|c|c|c|c|c|}
\hline \multirow{2}{*}{ Classe de consumo } & \multicolumn{7}{|c|}{ Tarifa média de energia (R\$/MWh) } & \multirow{2}{*}{$\begin{array}{c}\text { Variação percentual } \\
\quad(2012-2018)\end{array}$} \\
\hline & 2012 & 2013 & 2014 & 2015 & 2016 & 2017 & 2018 & \\
\hline Comercial e serviços & 622 & 502 & 558 & 726 & 655 & 711 & 741 & 19,1 \\
\hline Industrial & 508 & 412 & 468 & 644 & 556 & 615 & 639 & 25,7 \\
\hline Residencial & 666 & 523 & 575 & 740 & 664 & 713 & 751 & 12,8 \\
\hline Rural & 384 & 314 & 350 & 471 & 428 & 464 & 476 & 23,8 \\
\hline Rural irrigante & 271 & 220 & 272 & 338 & 309 & 331 & 367 & 35,1 \\
\hline Serviço de água, esgoto e saneamento & 421 & 342 & 396 & 530 & 466 & 512 & 522 & 24,0 \\
\hline
\end{tabular}

Fonte: Aneel.

Obs.: Tarifas de energia com tributos, referentes ao mês de dezembro de cada ano, atualizadas pelo Índice Nacional de Preços ao Consumidor Amplo (IPCA). 
Meta $7.2(\mathrm{ONU})$ - Até 2030, aumentar substancialmente a participação de energias renováveis na matriz energética global.

Meta 7.2 (Brasil) - Até 2030, manter elevada a participação de energias renováveis na matriz energética nacional.

Essa meta foi alterada para o caso brasileiro porque o país já detém participação elevada de energias renováveis na matriz energética nacional, não tendo sentido, portanto, comprometer-se a elevá-la, mas, sim, a continuar no objetivo de mantê-la elevada ao longo do tempo. Considerando-se toda a matriz energética brasileira (não apenas a elétrica), a participação de fontes renováveis passou de 42,4\% em 2012 para 43,2\% em 2017 e, permanecendo nesse ritmo, alcançará os 45,0\% antes de 2030 - esse foi o compromisso assumido pelo Brasil no Acordo de Paris.

A capacidade instalada da fonte hidráulica na matriz energética caiu de 13,8\% para 11,9\% entre 2012 e 2017, apesar da contínua expansão absoluta em termos de novas usinas e da capacidade geradora. Isso se deve ao crescimento das demais fontes renováveis (eólica, solar e bioenergética), que saltaram de 28,6\% para 31,2\% no mesmo período. Esses resultados também indicam que o Brasil alcançará, em 2030, as metas pactuadas no Acordo de Paris de elevar para 33,0\% a participação de fontes renováveis (exceto hidráulica) e, mais especificamente, para 18,0\% a participação da bioenergia (derivados de cana-de-açúcar, madeiras etc.).

Enquanto o conjunto das fontes não renováveis apresentou queda na participação da capacidade instalada na matriz energética brasileira, o gás natural, especificamente, passou de $11,5 \%$ para $12,9 \%$, devido a avanços tecnológicos que melhoraram sua competitividade em relação a outras fontes térmicas, mas também por constituir uma fonte de energia de transição mais limpa que os tradicionais óleo diesel e óleo combustível.

\section{TABELA 2}

Oferta interna de energia na matriz energética - Brasil (2012 e 2017)

\begin{tabular}{|c|c|c|c|c|}
\hline \multirow{2}{*}{ Fontes de energia } & \multicolumn{2}{|c|}{2012} & \multicolumn{2}{|c|}{2017} \\
\hline & 1 mil tep & $\%$ & 1 mil tep & $\%$ \\
\hline Não renováveis & 163.365 & 57,6 & 166.808 & 56,8 \\
\hline Petróleo e derivados & 111.193 & 39,2 & 106.276 & 36,2 \\
\hline Gás natural & 32.598 & 11,5 & 37.938 & 12,9 \\
\hline Carvão mineral e derivados & 15.287 & 5,4 & 16.570 & 5,6 \\
\hline Urânio e derivados & 4.286 & 1,5 & 4.193 & 1,4 \\
\hline Outras não renováveis ${ }^{1}$ & - & - & 1.831 & 0,6 \\
\hline Renováveis & 120.242 & 42,4 & 126.685 & 43,2 \\
\hline Hidráulica e eletricidade & 39.181 & 13,8 & 35.023 & 11,9 \\
\hline Lenha e carvão vegetal & 25.735 & 9,1 & 23.424 & 8,0 \\
\hline Derivados de cana-de-açúcar & 43.572 & 15,4 & 51.116 & 17,4 \\
\hline Outras renováveis ${ }^{2}$ & 11.754 & 4,1 & 17.122 & 5,8 \\
\hline Total & 283.607 & 100,0 & 293.492 & 100,0 \\
\hline
\end{tabular}

Fonte: Brasil (2013; 2018).

Notas: ${ }^{2}$ Gás de alto forno, de aciaria e de enxofre.

${ }^{2}$ Lixívia, biodiesel, eólica, solar, casca de arroz, biogás, resíduos de madeira, gás de carvão vegetal e capim elefante.

Obs.: Tep - toneladas equivalentes de petróleo.

Meta $7.3(O N U)$ - Até 2030, dobrar a taxa global de melhoria da eficiência energética.

Meta 7.3 (Brasil) - Até 2030, aumentar a taxa de melhoria da eficiência energética da economia brasileira.

O Plano Decenal de Expansão de Energia (PDE) 2027 projetou a contribuição dos ganhos de eficiência energética para o fornecimento total de energia até 2027, considerando os padróes tecnológicos do ano-base, 2017. A eficiência energética, entendida como o inverso da intensidade energética, funciona como uma proxy da eficiência energética da economia como um todo. 
$\mathrm{Na}$ energia elétrica, a economia projetada será de $41 \mathrm{TWh}$, o que equivale à geração de uma hidroelétrica de 10 GW. Essa é a capacidade instalada da porção brasileira de Itaipu e da usina de Xingó. Em termos de combustível economizado, a projeção é de 318 mil barris de petróleo por dia, o que corresponde a 10\% da produção de petróleo do Brasil em 2017. Do ponto de vista setorial, a economia energética será de $6 \%$ nos setores produtivos (indústria, comércio e serviços, agropecuária e transportes) e $4 \%$ no consumidor residencial.

As projeçôes foram calculadas com base no alcance de diversas açóes do Estado brasileiro nessa área, como o Programa Brasileiro de Etiquetagem (PBE), o Programa Nacional de Conservação de Energia Elétrica (Procel), o Programa Nacional da Racionalização do Uso de Derivados de Petróleo e do Gás Natural (Conpet), o Programa de Eficiência Energética da Aneel, e na atuação do Comitê Gestor de Índices de Eficiência Energética (CGIEE), coordenado pelo MME. De forma geral, esses programas trabalham com a definição de padróes regulatórios que estabelecem níveis mínimos de eficiência energética de produtos comercializados no país e a aplicação de recursos em projetos de eficiência energética a serem desenvolvidos dentro da área de concessão de cada distribuidora de energia elétrica.

Meta 7.a (ONU) - Até 2030, reforçar a cooperação internacional para facilitar o acesso a pesquisa e tecnologias de energia limpa, incluindo energias renováveis, eficiência energética e tecnologias de combustiveis fósseis avançadas e mais limpas e promover o investimento em infraestrutura de energia e em tecnologias de energia limpa.

Meta 7.a (Brasil) - Meta mantida sem alteração.

Para colaborar com os esforços internacionais de desenvolvimento energético sustentável, o Brasil reforçou seu engajamento nas principais organizaçôes e iniciativas sobre o tema.

Em 2018, o país tomou a decisão de ingressar na Agência Internacional de Energia Renovável (Irena) para disseminar globalmente sua experiência em planejamento energético de longo prazo, na formatação de leilóes de energia renovável, no uso de hidroeletricidade e na integração de sistemas elétricos e bioenergia.

Em 2017, o país tornou-se associado da Agência Internacional de Energia (AIE), com a qual cooperava desde 2006. Essa organização dedicou capítulo especial ao Brasil em seu World Energy Outlook de 2013, em que analisou detalhadamente as perspectivas brasileiras para o setor de energia e as implicaçóes para o cenário energético global. Em 2018, a AIE lançou nova edição do relatório de mercado sobre energias renováveis, que, em boa parte, graças à colaboração com o Brasil, destacou o papel da bioenergia como o "gigante oculto" das energias renováveis, cujo papel será imprescindível para o cumprimento dos objetivos do Acordo de Paris e dos ODS.

Meta 7.b (ONU) - Até 2030, expandir a infraestrutura e modernizar a tecnologia para o fornecimento de serviços de energia modernos e sustentáveis para todos nos paises em desenvolvimento, particularmente nos paises de menor desenvolvimento relativo, nos pequenos Estados insulares em desenvolvimento e nos países em desenvolvimento sem litoral, de acordo com seus respectivos programas de apoio.

Meta 7.b (Brasil) - Até 2030, expandir a infraestrutura e aprimorar a tecnologia para o fornecimento de serviços de energia modernos e sustentáveis para todos.

As usinas hidroelétricas são a principal fonte renovável do país, com 63,8\% da capacidade total de geração, em 2018, comparada com 67,9\%, em 2013. A participação caiu apesar da construção de 294 usinas no período a maioria constituída de pequenas centrais hidroelétricas - e da elevação de 87,3 mil MW para 100,3 mil MW da capacidade. A diminuição relativa das hidroelétricas ocorreu porque a fonte renovável que mais tem crescido no Brasil é a eólica, que passou de menos de 2,0\% da capacidade total, em 2013, para 9,1\%, em abril de 2019. Assim, o país ocupou o quinto lugar no ranking mundial de capacidade eólica nova instalada em 2018 , atrás de China, Estados Unidos, Alemanha e Índia. No total são 642 usinas com mais de 7 mil turbinas eólicas, com capacidade de 14,4 mil MW. 
No caso da energia solar, a expansão foi lenta até 2016, mas se acelerou de 2017 em diante, em virtude do rápido crescimento da geração centralizada e da produção de energia pelos próprios consumidores, a geração distribuída (GD); esta, que contava com apenas 7,4 mil unidades instaladas em 2016, saltou para 71,4 mil em abril de 2019. Apesar desses números, a contribuiçáo da energia solar para a capacidade total de geração de energia elétrica ainda é residual (1,7\% da capacidade total instalada, em abril de 2019).

Pelo lado das fontes não renováveis - basicamente combustíveis fósseis -, o Brasil viu sua participação relativa reduzir-se de 19,8\% em 2013 para 15,6\% da capacidade total em 2018.

\section{IMPLICAÇÕES DE POLÍTICAS PÚBLICAS}

Por utilizar fontes mais limpas na geraçáo de eletricidade e por parte de seus combustíveis provirem de fontes renováveis, o Brasil ocupa a 11ª posição no mundo em emissóes de gás carbônico, provenientes da combustấo de derivados de petróleo e carvão e da indústria. As emissóes brasileiras foram de apenas 1,4\% do total mundial em 2015; China e Estados Unidos, os maiores poluidores, responderam por 43,6\%. Também as emissóes per capita do Brasil estáo entre as menores do mundo: 2,17 t métricas contra a média de 8,12 t métricas per capita dos vinte países mais poluidores.

Diversas políticas atuam em apoio aos investimentos em energias renováveis, a exemplo dos financiamentos do Banco Nacional de Desenvolvimento Econômico e Social (BNDES) aos investimentos em parques eólicos e das linhas de crédito do programa Fundo Clima, voltadas à geração de energia limpa e ao desenvolvimento tecnológico da cadeia produtiva das renováveis. Outro mecanismo essencial são os leilōes de contratação de energia da Aneel, que estimulam investimentos e permitem maior diversificação na oferta de energia. Uma política recente é o RenovaBio, voltado à expansão da produçấo e do uso de biocombustíveis na matriz energética nacional, e que objetiva promover mais rapidamente a "descarbonização" do mercado de combustíveis no país.

\section{REFERÊNCIAS}

BRASIL. Ministério de Minas e Energia. Resenha energética brasileira - exercício de 2012. Brasília: MME, maio 2013. Disponível em: <https://bit.ly/2YHnMYO >.

. Ministério de Minas e Energia. Resenha energética brasileira 2018 - ano base 2017. Brasília: MME, jun. 2018. Disponível em: <https://bit.ly/2OUxnlh>.

REN21. Renewables 2019 - global status report. Paris: REN21, 2019. Disponível em: <https://bit.ly/2Nbv6qn>. 
